\title{
Direct Composite Resin for the Management of Tooth Wear: A Systematic Review
}

This article was published in the following Dove Press journal:

Clinical, Cosmetic and Investigational Dentistry

Disha Vajani'

Tameeza Hassanali Tejani (iD) Alexander Milosevic $\mathbb{D}^{2}$

'Hamdan Bin Mohammed College of Dental Medicine, Mohammed Bin Rashid University (MBRU) of Medicine and Health Sciences, Dubai, United Arab Emirates; ${ }^{2}$ Department of Prosthodontics, Hamdan Bin Mohammed College of Dental Medicine, Mohammed Bin Rashid University (MBRU) of Medicine and Health Sciences, Dubai, United Arab Emirates
Correspondence: Alexander Milosevic Email alex.milosevic@outlook.com
Background: This study systematically reviewed survival of direct composite to restore worn teeth.

Materials and Methods: A comprehensive electronic search of databases sourced from Medline-PubMed, Embase, Cochrane Central, Scopus, Google scholar was performed on literature published between January 1990 and December 2018. Grey literature was also reviewed. Data extraction included sample size, number of composite restorations, operators, composite type, mean or total follow-up time and success rate expressed as either percent of successful restorations or median survival time (MST). Methodological quality was rated using the Joanna Briggs Institute appraisal checklist for case series. Studies on children, noncarious cervical lesions, cast and all-ceramic restorations, case reports and case series with $<5$ participants were excluded.

Results: A total of 1563 studies were identified and 1472 were screened. Sixty-two full-text papers were assessed for eligibility which resulted in 10 studies that met inclusion criteria. These were mainly case series and assessed 3844 direct composite restorations placed in 373 patients mostly in hospital settings. Survival ranged from $50 \%$ to $99.3 \%$. Methodological quality improved from the earlier studies and was rated low to moderate in 7 studies and good in 3. The funnel plot showed a low risk of publication bias but there was considerable heterogeneity $\left(\mathrm{I}^{2}=97.7 \%\right)$. There was a non-significant weak negative association between age and survival (Spearman's rho=-0.12).

Conclusion: Qualitative evaluation of the studies proved difficult because of the nature of case series but reporting improved in the later studies. Despite the generally short duration of studies, small sample sizes in terms of patient numbers and composite restorations, the survival rates of direct hybrid composite resin in the short to medium term are acceptable and support their application for the restoration of worn teeth.

Keywords: systematic review, direct composite, tooth wear

\section{Introduction}

The survival of direct composite resin for the restoration of the worn dentition has been described in several studies. There was a lack of evidence, however, on what is the best way to restore the worn dentition, which was the title of a dental evidence-based topic (DEBT) published in 2011. ${ }^{1}$ The main advantage of direct composite over conventional approaches for restoration of the worn dentition is that it embraces an additive, minimally invasive approach advocated by the European consensus statement. ${ }^{2}$

Three systematic reviews, published in 2014 and two in 2016, assessed the rehabilitation of worn teeth. ${ }^{3-5}$ None were able to produce a meta-analysis and the 
assessment of bias was determined in only one study. Since the time scale between the three meta-analyses was narrow, the included survival studies were similar if not the same. All the included studies appeared to be of a case series design with a mix of retrospective and prospective design, mostly without randomisation and thus with a high risk of bias, which could exaggerate or underestimate the real effect of the intervention. Furthermore, a range of treatment modalities was included in the reviews. Qualitative measures of the risk of bias, such as Cochrane, ROBINS-I, Newcastle-Ottawa and Downs and Black are indicated for randomised, non-randomised or observational studies such as case-control or cohort studies and not for case series. ${ }^{6-8}$ Two methodological quality tools for case series of an intervention without a comparison group exist. ${ }^{9,10}$ A simple tool for evaluating the quality of case series described by Murad et al has 4 domains with 8 binary questions which can be aggregated into a score. ${ }^{9}$ The Joanna Briggs Institute checklist has 10 points or questions and is a case series critical appraisal tool. ${ }^{10}$ It is more applicable to tooth wear treatment studies on cases than the tool by Murad et al as it does not have a causality domain.

The first systematic review aimed to look for similar treatment options for generalized tooth wear and to recommend the best method to rehabilitate worn teeth using the best evidence available at that time. ${ }^{3}$ A search conducted from 2003 to 2013 with various search terms analysed clinical steps that included diagnostic waxing (DW), occlusal positioning (OP), vertical dimension increase (VDI), restoration and follow-up. According to the study, there was not enough evidence to form conclusions and they recommended more clinical research. ${ }^{3}$

Ahmed and Murbay systematically reviewed the survival of resin composites in the anterior region for the management of tooth wear. ${ }^{4}$ Six hundred and sixty-six articles were selected for the systematic review of which eight articles were full text reviewed. Only five articles were selected of which three were prospective and two were retrospective studies. The total number of restorations placed was 772 direct and indirect composites in 100 patients with follow-up ranging from 5 months to 10 years. At 2 years the survival rate was $90 \%$ and at 5 years it was $50 \%$. The posterior occlusion re-established by 18 months in $91 \%$ of patients after increasing the vertical dimension. Thus, the authors concluded that anterior composites can be used to increase the vertical dimension for short- and medium-term management of wear. ${ }^{4}$
The rehabilitation of severely worn teeth with various materials estimated the annual failure rates (AFR) for each of the 12 studies selected for the systematic review. ${ }^{5}$ A total of 511 articles were found of which 23 were accepted for full-text analysis as well as 7 papers found from hand searching. The AFR was $0.4 \%$ for microhybrid and $26.3 \%$ for microfilled direct resin composite. For indirect composites, the AFR ranged from $0 \%$ to $14.9 \%$ and $2.7 \%$ for porcelain veneers. The authors concluded that both direct and indirect methods can be used to treat severely worn teeth and did not reach a conclusion regarding which method was superior. ${ }^{5}$

Of the 3 previous systematic reviews, two followed the PRISMA reporting guidelines and one assessed bias risk. None of the studies reported on publication bias in the form of Eggers regression or funnel plot and none were able to provide a meta-analysis of an estimated pooled effect size for survival of direct composite. Here lies a major difficulty as meta-analysis aims to integrate studies with outcomes that are comparable and to synthesise the data from all the studies into an estimated effect size or outcome. The studies that have hitherto been published on direct composite to restore the worn dentition have expressed outcomes as percent survival over a time period, failure rates as percentages or median survival time. These different outcome measures do not allow instant comparisons to be made and moreover risk of bias tools are aimed at observational and randomised studies. An alternate outcome has been the clinical performance of composite restorations measured against the USPHS/Ryge criteria which is not intended for survival analysis.

The first systematic review by Muts et al (2014) had inclusion and exclusion criteria that were susceptible to selection bias. ${ }^{3}$ For instance, studies describing 'highly invasive, esthetically disappointing, complicated, nonrepairable or expensive treatments' were excluded thus potentially exaggerating the beneficial effect of the treatment stages that were investigated although the authors did recognise that the evidence was not strong enough to form conclusions. Furthermore, the review did not investigate any outcomes of treatment for tooth wear but aimed to identify similarities among treatment steps which were diagnostic waxing, centric relation and use of an interim appliance at the increased vertical dimension. The outcome of anterior composite survival in the 5 studies systematically reviewed by Ahmed and Murbay (2016) was reported to be "favourable" in the short to medium term with over $90 \%$ survival at 2.5 years and over $50 \%$ at 5 
years. ${ }^{4}$ The level of evidence was noted to be limited because of small sample sizes and heterogeneity between studies, although the $\mathrm{I}^{2}$ statistic was not reported. The systematic review by Mesko et al (2016) provided some evidence for the rehabilitation of tooth wear with risk of bias analysis using the Downs and Black scale..$^{5}$ This checklist, however, has an aggregate score for 27 items but the authors reported on 6 specific biases as being either low, high or unclear risk and furthermore the treatment modalities ranged widely as the 12 included studies reported on porcelain veneers, metal palatal veneers, direct and indirect composites as well as including both original and follow-up studies of the same participants such as Schmidlin et al (2009)/Attin et al (2012). ${ }^{11,12}$ A comparable single outcome such as survival or failure rates between all 12 studies was not presented and heterogeneity was not assessed.

This study aimed to identify and systematically review studies that assessed survival or failure of direct composite resin in the treatment of worn teeth irrespective of aetiology. This systematic review aimed to answer the focussed question "What is the survival of direct composite resin in the restoration of tooth wear?"

\section{Materials and Methods}

This systematic review followed the Preferred Reporting Items for Systematic Reviews and Meta-analysis (PRISMA) statement and was registered at the NIH International Prospective Register of Systematic Reviews, PROSPERO (CRD42019119929). ${ }^{13}$

\section{Eligibility Criteria}

Only original studies of composite survival or failure on patients with worn teeth described as either erosion, abrasion, attrition, tooth wear or worn teeth were included. Clinical performance of composites, often assessed using indices such as the USPHS (Ryge system), were excluded if these studies did not use direct composite and outcome was performance (secondary caries, discolouration) as opposed survival or failure. The PICOS format was used to define the study design for inclusion and exclusion criteria (see Table 1). A methodological problem regarding this review was that studies of direct composite were without comparison/controls and generally not randomised to treatment groups but conducted as case series and published as such or as case reports. Given their inherent low quality of evidence it was decided to only include case series/reports if the number of cases was $\geq 5$ subjects based
Table I Eligibility Criteria for the Systematic Review Based on $\mathrm{PICO}$

\begin{tabular}{|c|c|c|}
\hline Domain & Inclusion Criteria & Exclusion Criteria \\
\hline $\begin{array}{l}\text { Population/ } \\
\text { Participants }\end{array}$ & $\begin{array}{l}\text { Adults of any age, } \\
\text { ethnicity and gender } \\
\text { Tooth wear including } \\
\text { erosion, abrasion and } \\
\text { attrition }\end{array}$ & $\begin{array}{l}\text { Children } \\
\text { Adults with Non- } \\
\text { Carious Cervical } \\
\text { Lesions } \\
\text { (NCCL; Class } \\
\text { V abrasion) }\end{array}$ \\
\hline Interventions & $\begin{array}{l}\text { Restoration of worn } \\
\text { teeth with direct } \\
\text { composite resin }\end{array}$ & $\begin{array}{l}\text { Indirect composite, } \\
\text { Cast (PFM) and all- } \\
\text { ceramic restorations, } \\
\text { removable prostheses }\end{array}$ \\
\hline $\begin{array}{l}\text { Control/ } \\
\text { Comparison }\end{array}$ & None & \\
\hline Outcomes & $\begin{array}{l}\text { Survival of restorations } \\
\text { expressed as survival } \\
\text { proportion or Annual } \\
\text { Failure Rate (AFR) or } \\
\text { median survival time (MST) }\end{array}$ & $\begin{array}{l}\text { Clinical performance } \\
\text { expressed by USPHS } \\
\text { criteria }\end{array}$ \\
\hline $\begin{array}{l}\text { Study } \\
\text { Designs }\end{array}$ & $\begin{array}{l}\text { Case series or cohort } \\
\text { studies with } \geq 5 \text { subjects, } \\
\text { randomized or non- } \\
\text { randomized to treatment } \\
\text { groups }\end{array}$ & $\begin{array}{l}\text { Case reports }<5, \\
\text { narrative reviews, other } \\
\text { systematic reviews and } \\
\text { meta-analyses }\end{array}$ \\
\hline
\end{tabular}

on the finding that the median number of patients in a case series was 7 whilst it was 4 in case reports. ${ }^{9}$

\section{Search Strategy}

A comprehensive electronic search for literature published between the period 1990 up to and including December 2018 was performed for articles published in Medline (PubMed), Scopus, Embase, Cochrane Central and Google Scholar (90 pages). The US National Institutes of Health trials register (clinicaltrials.gov) was reviewed for unpublished data and ongoing research. Two authors (DJV and TT) assessed all titles and abstracts for inclusion independently without blinding to author identity or their institution and at each stage of the review. Manual searches of the bibliographies of all full-text articles and related reviews were performed. When it was necessary, authors were contacted for clarification, as in longitudinal studies with multiple publications from the same research group. The search terms are shown in Table 2. Hand searching of major journals was conducted along with reviewing of the reference lists of relevant articles. After screening, full-text publications were assessed for 
Table 2 Search Terms

\begin{tabular}{|c|c|}
\hline $\begin{array}{l}\text { I. Restoration of } \\
\text { Tooth Wear }\end{array}$ & $\begin{array}{l}\text { (Restoration[All Fields] AND (“tooth } \\
\text { wear"[MeSH Terms] OR (“tooth"[All } \\
\text { Fields] AND “wear"[All Fields]) OR "tooth } \\
\text { wear"[All Fields])) AND (“I990/0I/ } \\
\text { 0I”[PDAT]: "20I8/I2/3I"[PDAT]) } \\
\text { Searches: I3I5 }\end{array}$ \\
\hline $\begin{array}{l}\text { 2. Direct restorations } \\
\text { and tooth wear }\end{array}$ & 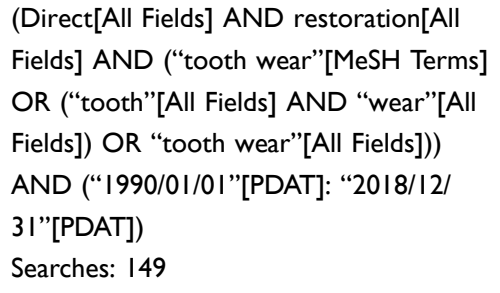 \\
\hline $\begin{array}{l}\text { 3. Direct composite } \\
\text { and erosion }\end{array}$ & $\begin{array}{l}\text { (direct[All Fields] AND composite[All } \\
\text { Fields] AND erosion[All Fields]) AND } \\
\text { (“I990/0I/0I”[PDAT]: "20I8/I2/ } \\
3 \mathrm{I} \text { [PDAT]) } \\
\text { Searches: } 6 \mathrm{I}\end{array}$ \\
\hline $\begin{array}{l}\text { 4. Direct restoration } \\
\text { and attrition }\end{array}$ & $\begin{array}{l}\text { (direct[All Fields] AND composite[All } \\
\text { Fields] AND ("tooth attrition”[MeSH } \\
\text { Terms] OR ("tooth”[All Fields] AND } \\
\text { "attrition"[All Fields]) OR “tooth } \\
\text { attrition"[All Fields] OR "attrition”[All } \\
\text { Fields])) AND (“I990/0I/0I”[PDAT]: } \\
\text { "20I8/I2/3I”[PDAT]) } \\
\text { Searches: } 26\end{array}$ \\
\hline
\end{tabular}

eligibility. Disagreements were resolved by discussion with the third author (AM) and consensus agreed. The PRISMA guideline/flowchart provided the template flowchart for literature searching and sifting.

\section{Quality Assessment}

The methodological quality was rated using the Joanna Briggs Institute (JBI) appraisal checklist for case series. ${ }^{10}$ For each of the 10 questions, a 'yes' gained 2 points, "no" gained 0 points and "unclear" gained 1 point. A maximum of 20 points was possible indicating high methodological quality for the study.

\section{Statistical Analysis}

It was not possible to perform quantitative analysis. Heterogeneity was quantified by using the $\mathrm{I}^{2}$ statistic. Reporting bias was assessed by funnel plot using Comprehensive Meta-Analysis Version 3 (Biostat, Englewood, NJ). To test for an association between age and survival SPSS v20 (Chicago, IL) was used with significance set at $\mathrm{p}<0.05$.

\section{Results}

Of the 13 studies registered on the NIH clinicaltrials.gov website, only 2 compared direct with indirect composite resin but neither had been completed and were thus not included. The electronic search identified 1551 titles and hand searching identified another 12 titles giving a total of 1563 titles (Figure 1). After removal of 91 duplicate titles, a total of 1471 abstracts were assessed for eligibility out of which 1410 abstracts were excluded as they were case reports with $<5$ subjects, reviews, restoration of noncarious cervical lesions, tooth wear effects on TMJ, etiology and guidelines, periodontics, anthropology, tooth brush abrasion or material science. A total of 62 full-text articles were reviewed out of which 48 articles were excluded of which one study by Poyser et al was excluded as it was reported as a follow-up study by Khayatt et al as a 7-year prospective study. ${ }^{14,15}$ A 3-year case series by Schimidlin et al was excluded also as it was continued as a 5.5-year study. ${ }^{11,12}$ A further 46 publications were reviews, indirect veneers and inlays, systematic reviews, case reports with $<5$ subjects, denture or material wear, orthodontics and splints and thus excluded from this systematic review. Gow and Hemmings placed Artglass, an indirect composite resin, which was also excluded from the systematic review, as was the study by Vailati et al who expressed results qualitatively as USPHS criteria. ${ }^{16,17}$ The principal author confirmed that the studies published by Hemmings et al (2000), Redman et al (2003) and Gulamali et al (2011) included the same cases and restorations reviewed at various times. ${ }^{18,19,22}$ Consequently, the first two of these studies were excluded. As a result, 10 studies were selected for inclusion in this systematic review. ${ }^{15,20-28}$ Determining study design was difficult but it appears that 3 studies involved retrospective review of entries in case records, ${ }^{21,23,27} 6$ studies were prospective and 1 was termed a randomised clinical study. Follow-up periods ranged from 1 to 10 years (Table 3). The sample size ranged from 7 to 164 patients with the number of direct composite restorations ranging from 31 to 1256 per study. These 10 publications assessed 3844 direct composite restorations placed in 373 subjects with survival ranging from $50 \%$ to $99.3 \%$ although follow-up periods differed widely. The study settings included university teaching clinics, dental hospitals and one private practice. Direct composites were used which varied from microfilled composite such as Durafill@ (Kulzer GmbH., Hanau, Germany), hybrid composite such as HerculiteC (Kerr Corporation, Orange, CA, USA) and nano-ceramic types 


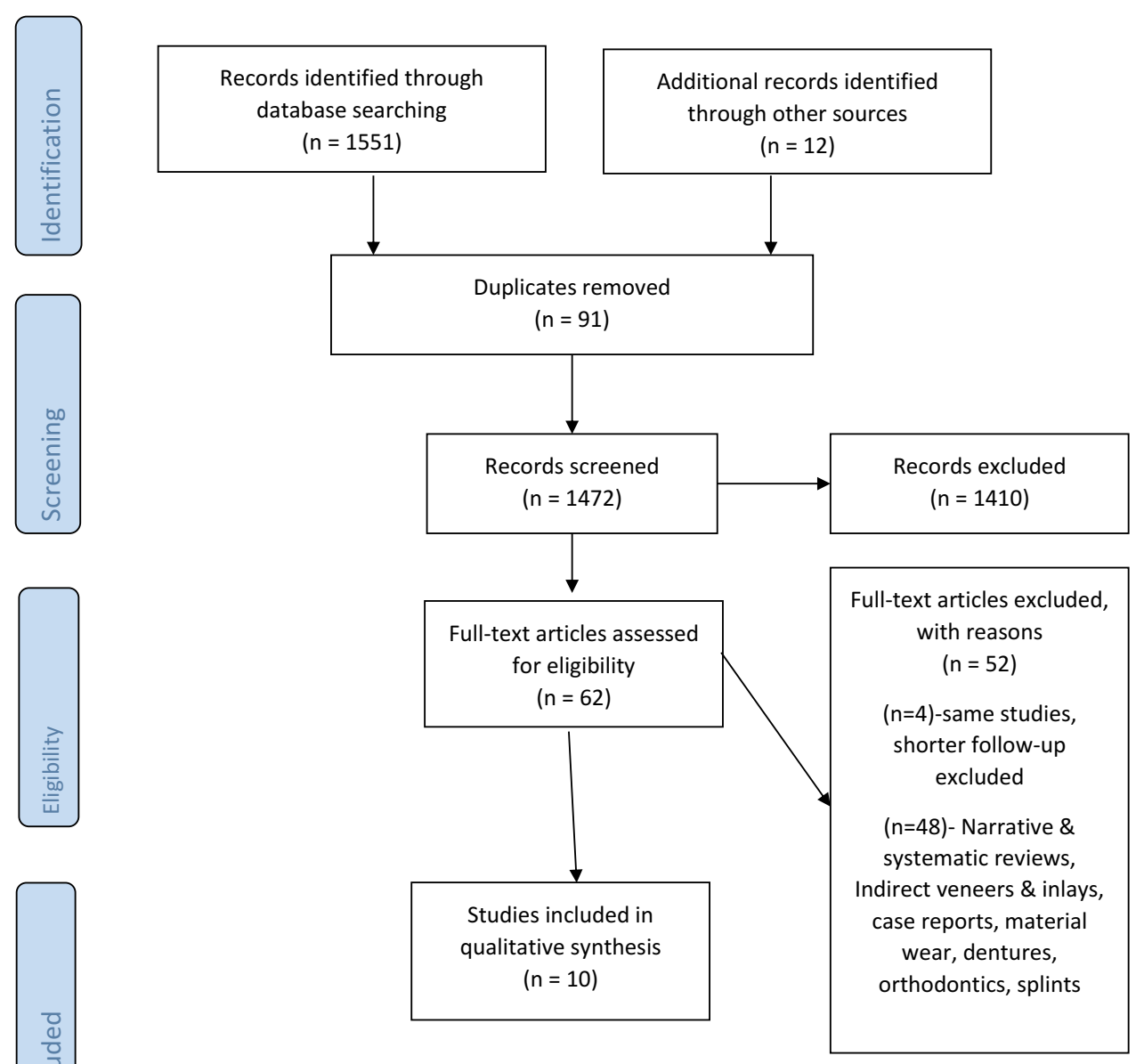

Figure I PRISMA flowchart of the systematic review.

such as Spectrum $\subset$ (Dentsply Sirona, York, PA 1740, USA), and Ceram X DuoC (Dentsply Sirona, York, PA 17,401, USA). One study used a two-step anterior technique whereby Clearfil AP-X (Kuraray, Japan) was placed palatally (also occlusally) and IPS Empress Direct (Ivoclar Vivadent, Liechtenstein) was used labially and incisally. All the studies incorporated an increase in OVD (Occlusal Vertical Dimension) except the study by Smales and Berekally. ${ }^{21}$ Tooth wear was located anteriorly, posteriorly or both locations. The number of operators varied from 1 specialist to 11 post-graduate specialty trainees in one study. Apart from the studies by Smales and Berekally, ${ }^{21}$ Hamburger et al, ${ }^{23}$ Milosevic and Burnside, ${ }^{25}$ and Bartlett and Varma, ${ }^{27}$ six included studies also assessed the clinical performance such as discolouration, marginal stain, secondary caries with either the modified USPHS criteria or FDI criteria. For comparative purposes, restoration survival is expressed as a percentage and Table 4 summarises the characteristics of the 10 included studies.

The risk of publication bias was assessed by funnel plot as shown in Figure 2. The funnel symmetry indicates low risk or possible absence of publication bias. Most of the studies are in the upper half of the funnel indicative of a reasonable degree of precision in those studies.

Table 3 shows the appraisal rating for quality of the included studies using the JBI checklist for case series.

The overall mean age of the 373 subjects in the 10 studies was 45 years. A negative but very weak association between age and restoration survival was found (Spearman's rho $=-0.12$ ) which was not statistically significant.

\section{Discussion}

The two systematic reviews published in 2016 focussed on anterior composites and rehabilitation of severe tooth 


\begin{tabular}{|c|c|c|c|c|c|c|c|c|c|c|}
\hline 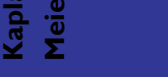 & 우 & $\stackrel{\mathscr{\nu}}{\check{\nu}}$ & $\stackrel{\tilde{\nu}}{\check{\nu}}$ & ż & $\stackrel{0}{z}$ & $\stackrel{\circ}{z}$ & $\stackrel{\tilde{y}}{\check{\nu}}$ & 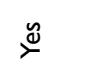 & $\stackrel{o}{z}$ & $\stackrel{\mathscr{\varpi}}{\check{\nu}}$ \\
\hline $\begin{array}{l}\frac{1}{0} \\
\bar{u} \\
\end{array}$ & ㅇ & ㅇ & $\stackrel{\check{\nu}}{\check{\nu}}$ & ㅇ & $\stackrel{y}{\check{\nu}}$ & $\stackrel{\tilde{\nu}}{\check{\nu}}$ & zo & $\stackrel{\tilde{\nu}}{\check{\nu}}$ & $\stackrel{\circ}{z}$ & $\stackrel{\mathscr{\nu}}{\succ}$ \\
\hline जै & $\stackrel{\circ}{\wedge}$ & よ̊ & ১ั่ํำ & ळั & ○ें & ळ̊ & ळે & ळ̊ & ळे & ڤ̊ \\
\hline 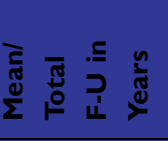 & 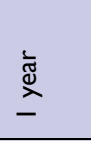 & 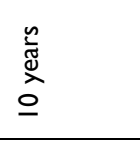 & $\begin{array}{l}\stackrel{n}{\bar{g}} \\
\stackrel{2}{0} \\
\underline{0}\end{array}$ & 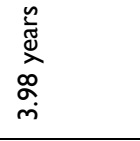 & 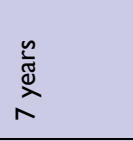 & 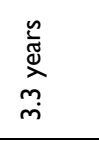 & 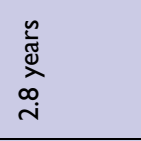 & 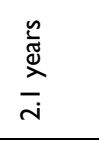 & $\sim$ & 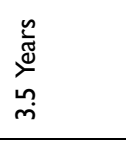 \\
\hline נִ & 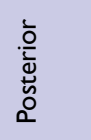 & 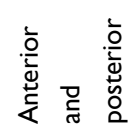 & 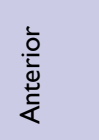 & 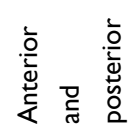 & 这 & 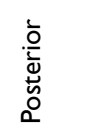 & 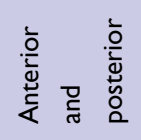 & 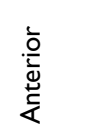 & 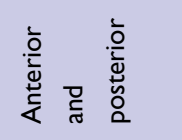 & 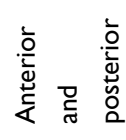 \\
\hline ठัّ & $\stackrel{\tilde{\nu}}{\nu}$ & ㅇ & $\stackrel{\check{\nu}}{\check{\nu}}$ & $\stackrel{\tilde{\nu}}{\tau}$ & $\stackrel{\check{\nu}}{\check{\nu}}$ & $\stackrel{\tilde{\nu}}{\tau}$ & $\stackrel{\tilde{\nu}}{\nu}$ & 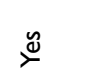 & $\stackrel{\tilde{y}}{\tau}$ & $\stackrel{\tilde{\Perp}}{\check{\nu}}$ \\
\hline 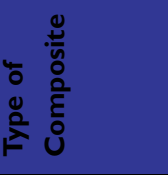 & $\begin{array}{l}\overline{\bar{E}} \\
\overline{\underline{\nu}} \\
\overline{\underline{\nu}}\end{array}$ & 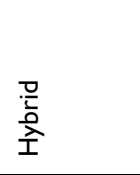 & 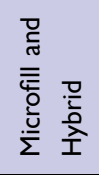 & 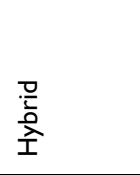 & 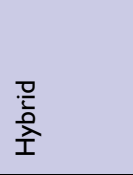 & $\begin{array}{l}\frac{0}{2} \\
\frac{0}{1} \\
\text { I }\end{array}$ & 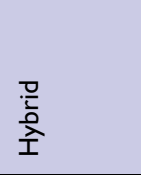 & 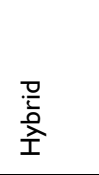 & 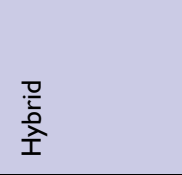 & 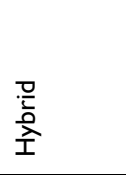 \\
\hline 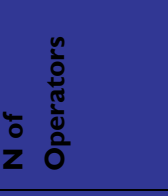 & - & $\sim$ & 洜 & - & - & $m$ & - & - & 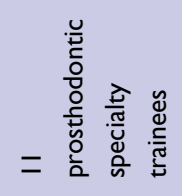 & in \\
\hline 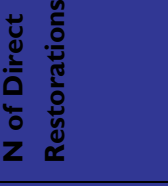 & $\bar{m}$ & ర్రి & 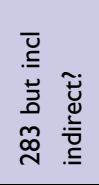 & స్లి & $\stackrel{\llcorner}{\infty}$ & $\stackrel{2}{\circ}$ & 응 & ๙ั & $\bar{\aleph}$ & $\stackrel{\text { ڤ̊ }}{\mathrm{N}}$ \\
\hline ⿸广 & $\Re$ & 守 & $\begin{array}{l}\frac{\infty}{\infty} \\
\stackrel{m}{m}\end{array}$ & $\stackrel{\infty}{\underset{f}{f}}$ & กี & $\stackrel{m}{q}$ & $\stackrel{\stackrel{m}{m}}{\frac{n}{n}}$ & $\stackrel{0}{\dot{m}}$ & ケ & 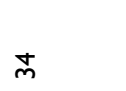 \\
\hline $\begin{array}{ll}\overline{0} \\
z\end{array}$ & 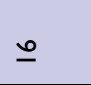 & $\simeq$ & సి & $\underline{\infty}$ & $\underline{\underline{n}}$ & $r$ & 志 & $\bar{\gamma}$ & $\stackrel{m}{m}$ & $\dot{m}$ \\
\hline 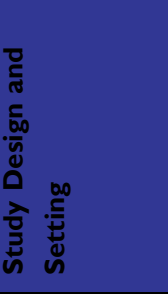 & 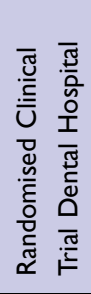 & 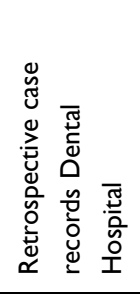 & 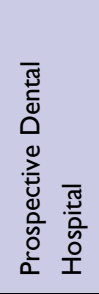 & 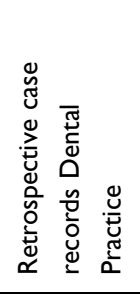 & 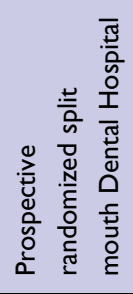 & 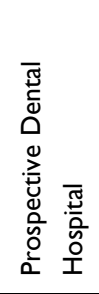 & 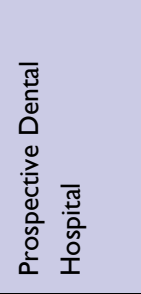 & 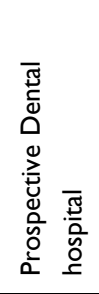 & 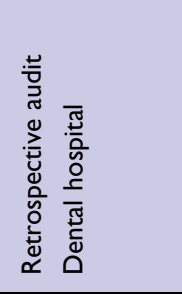 & 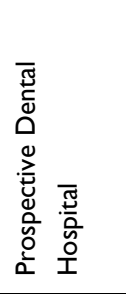 \\
\hline 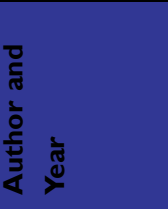 & 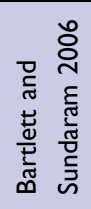 & 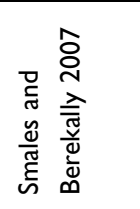 & 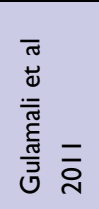 & 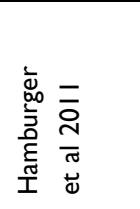 & 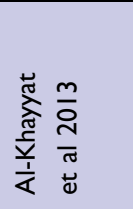 & 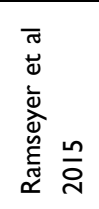 & 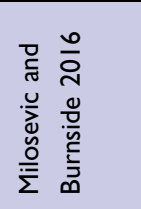 & 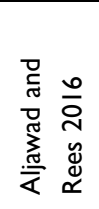 & 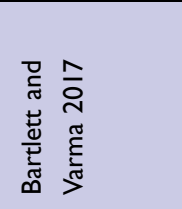 & 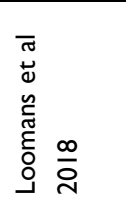 \\
\hline $\bar{n} z$ & - & $N$ & $m$ & $\sigma$ & in & 0 & $n$ & $\infty$ & $\sigma$ & 으 \\
\hline
\end{tabular}


Table 4 Rating Scales for the 10 Studies

\begin{tabular}{|c|c|}
\hline Study & $\begin{array}{l}\text { Joanna Briggs Institute (JBI) } \\
\text { Quality Appraisal Checklist for } \\
\text { Case Series }\end{array}$ \\
\hline Bartlett and Sundaram $2006^{20}$ & Low \\
\hline Smales and Berekally $2007^{21}$ & Low \\
\hline Gulamali et al $2011^{22}$ & Moderate \\
\hline Hamburger et al $201 \mathrm{I}^{23}$ & High \\
\hline Al-Khayyat et al $2013^{15}$ & Moderate \\
\hline Ramseyer et al $2015^{24}$ & Moderate \\
\hline Milosevic and Burnside $2016^{25}$ & High \\
\hline Aljawad and Rees $2016^{26}$ & Moderate \\
\hline Bartlett and Varma $2017^{27}$ & Moderate \\
\hline Loomans et al $2018^{28}$ & High \\
\hline
\end{tabular}

wear. ${ }^{4,5}$ Six studies were reviewed in the anterior composite review, but of these, Hemmings (2000), Redman (2003) and Gulamali (2011) all had the same patients albeit further cases were added later using other materials. ${ }^{18,19,22}$ The same issue occurred in the study on severe tooth wear rehabilitation. ${ }^{5}$ This means that both previous systematic reviews included the initial publication and follow-up survival studies as if they were independent separate data on survival or failure but in fact were the same restorations. This highlights the difficulty facing reviewers when longitudinal studies with successive publications do not specify that outcomes are a follow-up of earlier published studies. Reviewers should be alerted to this possibility if a single research group publishes sequential survival data over increasing time periods. Only the most recent study should be reviewed, and this is especially important should meta-analysis be performed. Determination of study design has also caused confusion as the same studies were classed as prospective in one systematic review and retrospective in the other., ${ }^{4,5}$

The 10 studies reviewed here are fewer than the previous systematic review by Mesko et $\mathrm{al}^{5}$ because this review focussed on one treatment modality, namely direct composite in the management of tooth wear. They reported it was surprising to find a huge diversity in outcomes with Annual Failure Rates from good to unacceptable although treatment modalities included in that systematic review varied widely with metal palatal veneers and indirect composite palatal veneers as well as direct composites. Indeed, within longitudinal follow-up publications, it was not always easy to determine the exact number of direct composites that survived. Although Gulamali et al stated that 283 composite resin restorations were placed in 26 patients, these were a combination of indirect and direct

Funnel Plot of Standard Error by Logit event rate

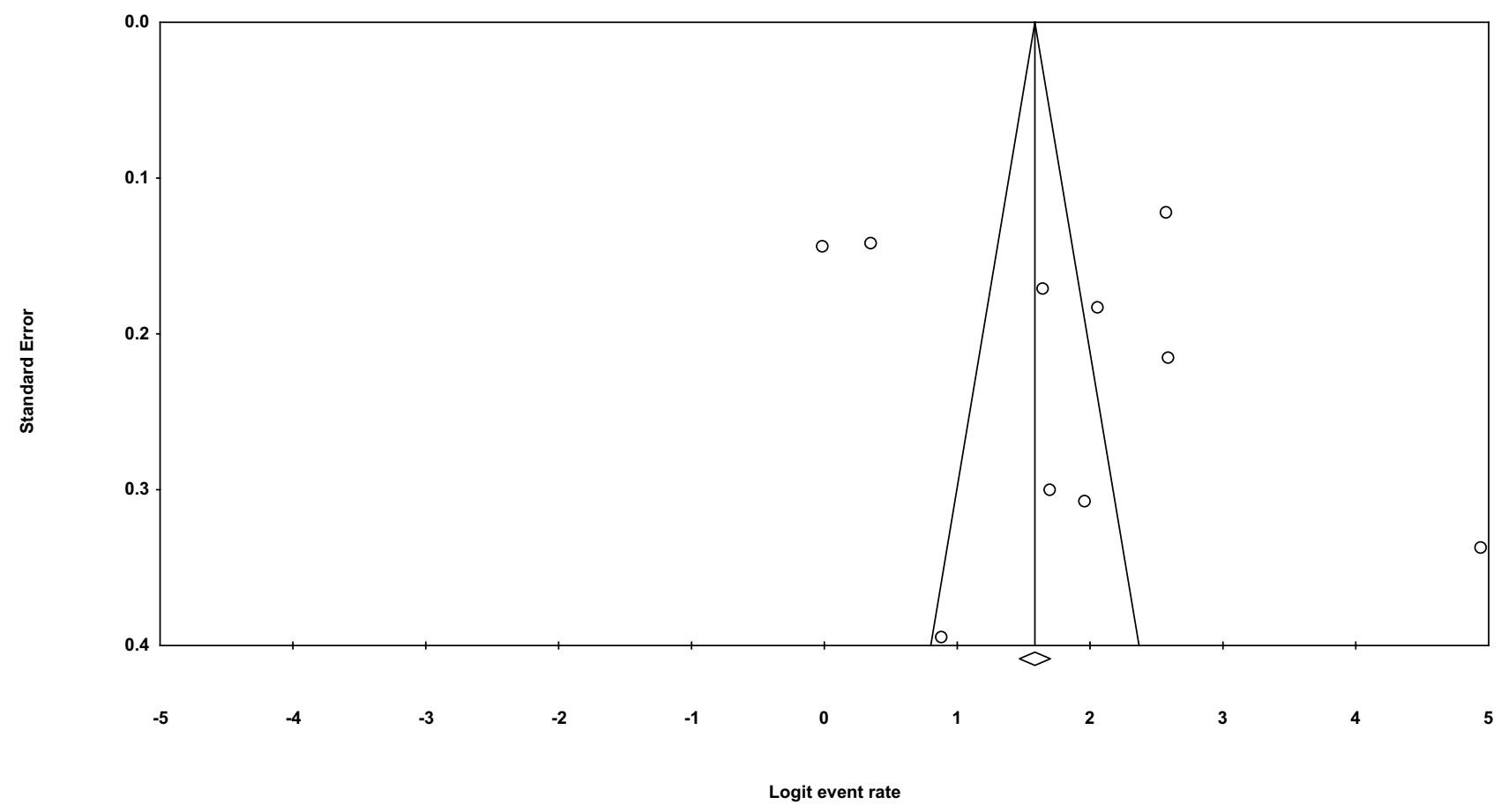

Figure 2 Funnel plot for the 10 included studies. 
with no clear indication of the number of direct composites that survived at the 10 -year review on 26 patients. ${ }^{22}$ It should be noted that in this systematic review not all the composites were of the same type.

Most of the studies reviewed here were prospective and most presented time-to-event data also known as survival data correctly. Such data have paired observations of the length of time no event was observed and whether at the end of the time period an event occurred, in this case, restoration failure, or the end of observation. The most appropriate method to summarize time-to-event data is to use survival analysis by Kaplan-Meier plots and express the intervention as a hazard ratio or Cox regression. ${ }^{29,30}$ Only half of the studies presented survival with KaplanMeier survival plots. $^{21,22,25,26,28}$

In restorations for caries, the mean annual failure rate of all posterior composites systematically reviewed from 12 studies at 5 and 10 years was $1.8 \%$ and $2.4 \%$, respectively, with higher failures in high caries risk patients and more restored surfaces. ${ }^{31}$ The survival rates presented here varied from $71 \%$ to $99.3 \%$ with later studies having better outcomes, possibly because of better methods, although follow-up periods varied. The survival of composites to restore worn surfaces is thus comparable to restoration of carious lesions. The wide variation in survival may be related to the difference in definition between studies as repaired restorations may be counted as survived rather than failed. Definitions of success and survival should be clearly stated. For clarity, this systematic review did not differentiate between the two. Treatment outcomes may also differ according to whether partial reconstruction or full mouth treatment was provided. It is likelier that partial reconstruction was the main treatment modality for most patients in the included studies as not every tooth is worn and not every patient is fully dentate particularly in studies with an older mean age of patients. Furthermore, few included studies specified composite survival as a function of complete or partial restoration.

Worn surfaces will tend to have a low configuration factor or C-factor which in theory should reduce stress at the bonded surfaces and improve survival. The survival of direct composites placed to restore worn teeth is generally very acceptable and more importantly embraces the philosophy of minimal intervention and a reversible approach as advocated by the European consensus statement. ${ }^{2}$ A recent systematic review introduced a new metric, the Annual Intervention Rate, which was an overall $11.6 \%$ for composite placed on occluding surfaces in the worn dentition. $^{32}$ Most of the studies reviewed here were included in that study and confirm that composite is appropriate but may need re-intervention.

A difficulty interpreting the data stems from the low evidence provided by case reports and case series. A case series has been defined as a study that makes observations on a series of individuals, usually all receiving the same intervention, with no control group. ${ }^{33}$ Risk of bias tools are aimed at observational studies with or without controls and randomised controlled trials. The included studies were mostly case series with none of the 10 studies having a control group although 2 studies had randomisation to compare whether tooth preparation influenced survival or to allocate material to the left or right sides of the mouth. ${ }^{14,20}$ The overall domains to evaluate bias can be classed into selection, ascertainment, causality and reporting. ${ }^{9}$ The choice of tool to evaluate methodological quality was therefore difficult but the Joanna Briggs Institute critical appraisal checklist for case series was applied as all the studies could be rated rather than a selected few as was done by Mesko et al who applied the Downs and Black scale and rated 3 of the 12 studies where there was some form of randomisation. The JBI checklist has 10 questions which must be answered "yes", "no", or "unclear" with a "not applicable" if needed. The authors in this study decided to apply scores although this is not part of the JBI appraisal. What was unclear to the reviewers was the overall JBI appraisal having categories of "include" or "exclude" which implied that studies should be rated prior to inclusion in the systematic review rather than after. For this review, the studies were rated if they met the inclusion criteria. Two questions considered noteworthy were the need for consecutive and complete inclusion of participants. The completeness of a case series contributes to its reliability. ${ }^{34}$ Consecutive inclusion of participants indicates a lower risk of selection bias and potential to exaggerate the effect or outcome under investigation if for instance possible cases are excluded based on age as it has been established that restoration survival is lower in older cases. ${ }^{25}$ Recruitment to most of the studies involved inclusion and exclusion criteria but most of the studies made no mention of consecutive or complete inclusion of participants. Overall, 2 studies were rated low quality, ${ }^{20,21} 5$ studies were rated moderate quality $^{15,22,24,26,27}$ and 3 were rated to have good methodological quality. ${ }^{23,25,28}$ The application of a Risk of Bias tool was considered for this systematic review but given that the studies were in effect cases series, it was decided not to apply such an assessment and meta-analysis cannot be applied to observational studies. In the systematic review by Mesko et al a risk of 
bias analysis was performed on 3 studies with most domains being classed as unclear risk of bias. ${ }^{5}$

Studies without control groups can provide information on long-term effectiveness, rare events and adverse events. ${ }^{35}$ All the studies described the condition, tooth wear, in terms of severity and/or location and described survival or failure rates although again there was no uniformity. Some studies presented survival or failures as percentage, others as median survival time (MST). The median age of failed restorations was deemed unreliable as it depended on the duration of the study with longer longitudinal studies potentially over estimating longevity. ${ }^{30}$

Non-comparative studies such as case reports and case series are considered the bottom of the pyramid in the hierarchy of evidence. Nevertheless, in attempting to understand the behaviour and survival of restorative materials in patients during function, the case series is valuable if selection, representativeness of cases and ascertainment of outcomes are described. ${ }^{9}$

The funnel plot is narrow and symmetrical indicative of a low risk of reporting bias which includes publication bias although there are outliers which is to be expected. The larger sized studies are likely to have greater precision or less error and thus will appear at the top of the funnel. Nine of the studies were performed in a dental hospital/university clinic setting so that settings were all very alike as were mean ages of the patients. Older patients have more severe wear which in turn is related to lower survival because less tooth structure is available for bonding and compromised teeth are more likely to be extracted. ${ }^{25}$ Although a weak negative association was found between age and survival, it was not significant. Only English language publications were included which could be a limitation of this review.

Heterogeneity is the variance between studies and can be clinical, methodological or statistical. The $\mathrm{I}^{2}$ statistic measures the latter and it was calculated to be $97 \%$ which is considerable. The clinical and methodological heterogeneity in the 10 studies are unknown but some judgment can be made regarding clinical heterogeneity. Although composite manufacturers and operators differed, in most studies a low number of operators placed hybrid composite restorations at an increased Occlusal Vertical Dimension (OVD), mainly using the total etch technique. Between study clinical heterogeneity, therefore, may not be wide, as supported by the excellent survival of direct composite in many of the later studies. Despite the small sample size of patients, half the studies having less than 20 subjects, and relatively short duration, it can be said that the studies were clinically relatively homogenous. The survival of direct composite to build up worn teeth is acceptable and a viable treatment modality. Long-term prospective studies with good sample size, however, are still needed.

\section{Conclusion}

Ten studies met the inclusion criteria for this systematic review on survival of direct composite for restoration of tooth wear. These studies spanned a 12-year period with those conducted in the last 5 years reporting an average $90 \%$ restoration survival rate albeit over the short to medium term. Qualitative evaluation of the studies proved difficult but reporting had improved in the later studies.

\section{Author Details}

Disha Vajani: Former postgraduate student in prosthodontics.

Tameeza Hassanali Tejani: Visiting lecturer in prosthodontics.

Alexander Milosevic: Former chair and program director in prosthodontics.

\section{Data Sharing Statement}

The abstracts and full papers that were reviewed are available on request and with the agreement of MBRU.

\section{Ethics Approval}

This study was exempt from ethics approval.

\section{Acknowledgment}

This work was for a dissertation in partial fulfilment of an $\mathrm{MSc}^{36}$

\section{Author Contributions}

All authors made a significant contribution to the work reported, whether that is in the conception, study design, execution, acquisition of data, analysis and interpretation, or in all these areas; took part in drafting, revising or critically reviewing the article; gave final approval of the version to be published; have agreed on the journal to which the article has been submitted; and agree to be accountable for all aspects of the work.

\section{Funding}

The postgraduate student, Disha Vajani,received an internal MBRU grant.

\section{Disclosure}

The authors report no conflict of interest in this work. 


\section{References}

1. Hurst D. What is the best way to restore the worn dentition? Evid Based Dent. 2011;12:55-56. doi:10.1038/sj.ebd.6400798

2. Loomans B, Opdam N, Attin T, et al. Severe tooth wear: European consensus statement on management guidelines. $J$ Adhes Dent. 2017;19:111-119.

3. Muts E-J, van Pelt H, Edelhoff D, Krejci I, Cune M. Tooth wear: a systematic review of treatment options. J Prosthet Dent. 2014;112 (4):752-759. doi:10.1016/j.prosdent.2014.01.018

4. Ahmed KE, Murbay S. Survival rates of anterior composites in managing tooth wear: systematic review. J Oral Rehabil. 2016;43 (2):145-153. doi:10.1111/joor. 12360

5. Mesko ME, Sarkis-Onofre R, Cenci MS, Opdam NJ, Loomans B, Pereira-Cenci T. Rehabilitation of severely worn teeth: a systematic review. J Dent. 2016;48:9-15. doi:10.1016/j.jdent.2016.03.003

6. Sterne JAC, Hernan MA, Reeves BC, et al. ROBINS-I: a tool for assessing risk of bias in non-randomised studies of interventions. BMJ. 2016;355:i4919. doi:10.1136/bmj.i4919

7. Deeks JJ, Dinnes J, D'Amico R, et al. Evaluating non-randomised intervention studies. Health Technol Assess. 2003;7:27. doi:103310/hta7270

8. Downs SH, Black N. The feasibility of creating a checklist for the assessment of the methodological quality both of randomised and non-randomised studies of health care interventions. J Epidemiol Community Health. 1998;52:377-384. doi:10.1136/jech.52.6.377

9. Murad MH, Sultan S, Haffar S, Bazerbachi F. Methodological quality and synthesis of case series and case reports. BMJ Evid Based Med. 2018;23:60-63. doi:10.1136/bmjebm-2017-110853

10. Moola S, Munn Z, Tufanaru C, et al. Chapter 7: systematic reviews of etiology and risk. In: Aromataris E, Munn Z, editors. Joanna Briggs Institute Reviewer's Manual. The Joanna Briggs Institute; 2017.

11. Schmidlin P, Filli T, Imfeld C, Tepper S, Attin T. Three-year evaluation of posterior vertical bite reconstruction using direct resin composite a case series. Oper Dent. 2009;34:102-108. doi:10.2341/08-11

12. Attin T, Filli C, Imfeld C, Schmidlin P. Composite vertical bite reconstructions in eroded dentitions after 5.5 years: a case series. J Oral Rehabil. 2012;39:73-79. doi:10.1111/j.1365-2842.2011.02240.x

13. Moher D, Liberati A, Tetzlaff J, Altman DG, The PRISMA Group (2009). Preferred Reporting Items for Systematic Reviews and MetaAnalyses: The PRISMA Statement. PLoS Med 6(7): e1000097. doi:10.1371/journal.pmed1000097

14. Poyser NJ, Briggs PFA, Chana HS, Kelleher MGD, Porter RWJ, Patel MM. The evaluation of direct composite restorations for the worn mandibular anterior dentition-clinical performance and patient satisfaction. J Oral Rehabil. 2007;34:361-376. doi:10.1111/j.13652842.2006.01702.x

15. Al-Khayatt A, Ray-Chaudhuri A, Poyser N, et al. Direct composite restorations for the worn mandibular anterior dentition: a 7 year follow-up of a prospective randomised controlled split-mouth clinical trial. J Oral Rehabil. 2013;40:389-401. doi:10.1111/joor.12042

16. Gow A, Hemmings K. The treatment of localised anterior tooth wear with indirect art glass restorations at an increased occlusal vertical dimension. Results after two years. Eur J Prosthodont Rest Dent. 2002;10 (3):101-105.

17. Vailati F, Gruetter L, Belser U. Adhesively restored anterior maxillary dentitions affected by severe erosion: up to 6 year results of a prospective clinical study. Eur J Esthet Dent. 2013;8(4):506-530.

18. Hemmings K, Darbar U, Vaughan S. Tooth wear treated with direct composite restorations at an increased vertical dimension: results at 30 months. J Prosthet Dent. 2000;83:287-293. doi:10.1016/S0022-3913(00) 70130-2
19. Redman CDJ, Hemmings KW, Good JA. The survival and clinical performance of resin-based composite restorations used to treat localised anterior tooth wear. $B r$ Dent J. 2003;194:566-572. doi:10.1038/sj. bdj.4810209

20. Bartlett D, Sundaram G. An up to 3- year randomized clinical study comparing indirect and direct resin composites used to restore worn posterior teeth. Int J Prosthodont. 2006;19:613-617.

21. Smales RJ, Berekally TL. Long-term survival of direct and indirect restorations placed for the treatment of advanced tooth wear. Eur J Prosthodont Restor Dent. 2007;15(1):2-6.

22. Gulamali A, Hemmings K, Tredwin C, Petrie A. Survival analysis of composite Dahl restorations provided to manage localised anterior tooth wear (ten year follow-up). Br Dent J. 2011;211:E9. doi:10.1038/sj. bdj.2011.683.

23. Hamburger JT, Opdam NJM, Bronkhorst EM, Kreulen CM, Roeters JJM, Huysmans M-C. Clinical performance of direct composite restorations for the treatment of severe tooth wear. J Adhes Dent. 2011;13(6):585-593.

24. Ramseyer ST, Helbling C, Lussi A. Posterior vertical bite reconstructions of erosively worn dentitions and the 'Stamp Technique' A case series with a mean observation time of 40 months. $J$ Adhes Dent. 2015;17:283-289.

25. Milosevic A, Burnside G. The survival of direct composite restorations in the management of severe tooth wear including attrition and erosion: a prospective 8-year study. J Dent. 2016;44:13-19. doi:10.1016/j. jdent.2015.10.015

26. Aljawad A, Rees J. Retrospective study of the survival and patient satisfaction with composite Dahl restorations in the management of localised anterior tooth wear. Eur J Prosthodont Rest Dent. 2016;24:222-229.

27. Bartlett D, Varma S. A retrospective audit of the outcome of composites used to restore worn teeth. Br Dent J. 2017;223:33-36. doi:10.1038/sj.bdj.2017.583

28. Loomans BAC, Kreulen CM, Huijs-Visser HECE, et al. Clinical performance of full rehabilitations with direct composite in severe tooth wear patients: 3.5 years results. J Dent. 2018;70:97-103. doi:10.1016/j.jdent.2018.01.001

29. Higgins JPT, Green S, editors. Cochrane Handbook for Systematic Reviews of Interventions Version 5.1.0 [Updated March 2011]. The Cochrane Collaboration; 2011.

30. Opdam NJM, Bronkhorst EM, Cenci MS, Huysmans M-C, Wilson NHF. Age of failed restorations: a deceptive longevity parameter. J Dent. 2011;39:225-230. doi:10.1016/j.jdent.2010.12.008

31. Opdam NJM, van de Sande FH, Bronkhorst EM, et al. Longevity of posterior composite restorations: a systematic review and meta-analysis. J Dent Res. 2014;93(4):943-949. doi:10.1177/0022034514544217

32. Kassardjian V, Andiappan M, Creugers NHJ, Bartlett D. A systematic review of interventions after restoring the occluding surfaces of anterior and posterior teeth that are affected by tooth wear with filled resin composites. J Dent. 2020;99:103388. doi:10.1016/j.jdent.2020.103388

33. Available from: https://community.cochrane.org/glossary. Accessed October 13, 2020.

34. Dekkers OM, Egger M, Altman DG, Vandenbroucke JP. Distinguishing case series from cohort studies. Ann Intern Med. 2012;156:37-40. doi:10.7326/0003-4819-156-1-201201030-00006.

35. Fitzpatrick-Lewis D, Ciliska D, Thomas $H$ The methods for the synthesis of studies without control groups; 2009. Hamilton, ON: National Collaborating Centre for Methods and Tools. Available from: http://www.nccmt.ca/pubs/non-RCT_EN.pdf.

36. Available from: https://repository.mbru.ac.ae/bitstream/handle/1/79/ 430.5-2019. 


\section{Publish your work in this journal}

Clinical, Cosmetic and Investigational Dentistry is an international, peer-reviewed, open access, online journal focusing on the latest clinical and experimental research in dentistry with specific emphasis on cosmetic interventions. Innovative developments in dental materials, techniques and devices that improve outcomes and patient

satisfaction and preference will be highlighted. The manuscript management system is completely online and includes a very quick and fair peer-review system, which is all easy to use. Visit http://www.dovepress.com/testimonials.php to read real quotes from published authors.

Submit your manuscript here: https://www.dovepress.com/clinical-cosmetic-and-investigational-dentistry-journal 